\title{
DERECHO CONSTITUCIONAL DE PETICIÓN AL SERVICIO DEL SISTEMA DE EVALUACIÓN DE IMPACTO AMBIENTAL
}

\author{
Francisco Javier González Silva \\ Profesor de Derecho Ambiental \\ Universidad Católica del Norte \\ Sede Coquimbo
}

La regulación del Sistema de Evaluación de Impacto Ambiental chileno nos señala que los proyectos o actividades señalados en el artículo 10 de la Ley 19.300 de Bases del Medio Ambiente, - desarrollado en profundidad en el Artículo 3 del Reglamento al Sistema de Evaluación de Impacto Ambiental -, sólo pueden ejecutarse previa evaluación ambiental de los mismos.

En efecto, el artículo 4 del Reglamento del Sistema de Evaluación de Impacto Ambiental señala que....... el Titular de un proyecto o actividad de los comprendidos en el artículo 3 del Reglamento al S.E.I.A. (Artículo10 de la Ley 19.300 de Bases del Medio Ambiente), o aquel que se acoja voluntariamente al Sistema, deberá presentar una Declaración de Impacto Ambiental, salvo que el proyecto $o$ actividad genere o presente alguno de los efectos, características o circunstancias contemplados en el artículo 11 de la L.B.M.A., - desarrollados en profundidad en los Artículos 5 a 11 del Reglamento al S.E.I.A.- , en cuyo caso deberá presentar un Estudio de Impacto Ambiental.

A mayor abundamiento, el Titulo III, Párrafo I, del Reglamento al S.E.I.A., relativo al Contenido de los Estudios de Impacto Ambiental, específicamente el artículo 12 letra e), exige presentar una descripción pormenorizada de aquellos efectos, características o circunstancias del artículo 11 de la L.B.M.A. (Artículos 5 a 11 del Reglamento al S.E.I.A.), que dan origen a la necesidad de efectuar un Estudio de Impacto Ambiental. A su vez, el Titulo III, Párrafo II, del Reglamento al S.E.I.A., relativo al Contenido de las Declaraciones de Impacto Ambiental, específicamente el artículo 15 letra c), exige presentar la indicación de los antecedentes necesarios para determinar si el impacto ambiental que generará o presentará el proyecto o actividad se ajusta a las normas ambientales vigentes, y los antecedentes necesarios para determinar que éste no requiere de la presentación de un Estudio, sino, tan solo, una Declaración de Impacto Ambiental.

Toda esta reglamentación ha significado que en la práctica, los titulares de los proyectos deban determinar previamente, en relación a sus proyectos o actividades, si se da alguno de aquellos efectos, características o circunstancias del artículo 11 de la L.B.M.A. (Artículos 5 a 11 del Reglamento al S.E.I.A.), que dan origen a la necesidad de efectuar un Estudio de Impacto Ambiental 
He observado con preocupación, que la determinación anterior, resulta tremendamente dificultosa de efectuar, considerando que el artículo 11 de la L.B.M.A. (Articulos 5 a 11 del Reglamento del S.E.I.A.) sólo establecen criterios generales que deben ser interpretados previamente por el titular del proyecto y que, ni siquiera, son de carácter normativo, a excepción, de los contenidos en la letra a) del artículo 5 y el establecido en la letra a) del artículo 6, ambos en relación con el artículo 7 del Reglamento al S.E.I.A.

En efecto, el artículo 7 del Reglamento al S.E.I.A. recién citado, señala que las normas de calidad y de emisión que se utilizarán como referencia para efecto de evaluar las circunstancias contenidas en la letra a) del artículo 5 y en la letra a) del artículo 6 , serán aquellas vigentes en la Confederación Suiza. Sin embargo esta, normativa no nos entrega todos los parámetros o estándares ambientales que puedan suplir a cabalidad los vacíos legales chilenos, en lo que a normas de calidad y emisión se refiere. Un ejemplo singular lo constituye el hecho de que la Confederación Suiza carece de norma de calidad ambiental aplicable a aguas marítimas.

Todo esto ha significado, - y la información estadística de que disponemos nos lo confirma,- que un porcentaje no despreciable de proyectos ingresan al Sistema por una vía equivocada, es decir a través de un E.I.A. en circunstancias que debieron hacerlo a través de una D.I.A., o viceversa, con los correspondientes perjuicios económicos y de tiempo que esto significa para los titulares de los proyectos.

Ciertamente resulta tremendamente importante y urgente consagrar una adecuada solución a esta gran dificultad. En este sentido, sugiero como forma para solucionar este difícil dilema, la siguiente : Someter esta difícil decisión a la propia autoridad ambiental, bajo el formato de un incidente de previo y especial pronunciamiento que debería ser resuelto por la autoridad sobre la base de la información proporcionada por el titular del proyecto.

Para esto, sería aconsejable canalizar este incidente previo utilizando el mismo concepto de ventanilla única. De esta manera, se permitiría obtener el pronunciamiento formal y fundado de los todos los organismos públicos correspondientes que tengan competencia ambiental en relación al proyecto o actividad a ejecutar.

La consagración legal de este incidente previo, permitiría al titular del proyecto tener de antemano una visión coincidente con la de la autoridad ambiental referente al cumplimiento de los criterios generales contemplados en el artículo 11 de la L.B.M.A. (Artículos 5 a 11 del Reglamento del S.E.I.A.) que determinan la pertinencia de una u otra vía de ingreso al S.E.I.A.. Sin lugar a dudas esto permitiría dejar preparado el camino a seguir en esta importante determinación y se facilitaría la entrada al Sistema sin el riesgo de equivocarse en el camino de ingreso escogido.

Naturalmente, este incidente previo, debería ser regulado en cuanto a los plazos que tendría la autoridad para resolverlo. Además, de lo resuelto por la autoridad ambiental debería otorgársele el carácter de vinculatorio para así dar seguridad jurídica al titular del proyecto de que este no será rechazado posteriormente invocándose como causal de rechazo el ingreso al Sistema por una vía equivocada.

Todo lo anterior se contribuiría también a hacer más expedito el proceso mismo de evaluación ambiental de los proyectos, evitando errores y otorgando aplicabilidad al objetivo de que la vía general de ingreso al Sistema sean las Declaración y, la excep- 
ción, sean los Estudio de Impacto Ambiental. De esta manera, se solucionaría la dificultad que se ha suscitado en la práctica donde se ha transformado a los Estudios en la regla general y a la Declaraciones de Impacto Ambiental en la excepción, cosa que, naturalmente, contraviene el espíritu de la legislación ambiental vigente.

Finalmente, quisiera señalar que, sin lugar a dudas, no es fácil proponer una modificación del Reglamento al S.E.I.A. en lo relativo a la difícil decisión a que se enfrenta el titular de un proyecto que ingresa al Sistema. Sin embargo, pienso que la idea de dar solución a este dilema, a través de la consagración de un incidente de previo y especial pronunciamiento que deba ser resuelto por la autoridad ambiental en base a los antecedente que proporcione el titular del proyecto, tiene un amparo y fundamento constitucional que radica simplemente en el Derecho de petición que nuestra propia Carta Fundamental contempla.

Recordemos que nuestra Constitución Política del Estado en el capítulo relativo a los Derechos y Garantías constitucionales consagra en el artículo 19 número 14 el Derecho de Petición, garantizándose a todas las personas....el Derecho a presentar peticiones a la autoridad, sobre cualquier asunto de interés público o privado, sin otra limitación que la de proceder en términos respetuosos y convenientes.

Pues bien, este Derecho constitucional de que gozan las personas, envuelve la obligación correlativa de la autoridad de dar respuesta a quiénes lo ejercen. En este sentido, podría incurrir en una infracción constitucional, con responsabilidades políticas y/o administrativas, la autoridad que no recibe y/o no da tramitación una petición formulada. $Y$ es lógico que así sea : No se concibe un real Derecho de Petición que no lleve envuelta esta obligación correlativa de responder formalmente, pues de lo contrario, se haría del ejercicio de este derecho un acto meramente ilusorio y no valdría la pena que esta garantía figurara en la Norma legal más importante de nuestro país : La Constitución Política del Estado. 